\title{
Introduction and methodology
}

\section{DEFINITION OF THE PROBLEM}

Databases are an indispensable tool in today's knowledge-based economy. Databases are not only a vast repository of invaluable knowledge but allow useful, fast and easy access to information. The private sector active, inter alia, in the fields of science, law, finance, travel and the public sector, including governments and the wider academic community, are increasingly dependent on databases to conduct business or research. Individuals also rely heavily on databases in their daily life, for instance to organize their travel, go to an event or simply watch television.

Not so long ago, most databases originated with governments. With the diminution of the role of the state and correlative increased privatization in many industrialized countries, the trend shifted and there are now many more databases made by the private sector. ${ }^{1}$ When databases were mainly made by government, the issue of their protection was not as acute. As the state created them with taxpayers' money, it did not take any financial risk and did not have to recoup its investment. Things are different for private entrepreneurs. Making a database generally requires considerable resources, in time, capital and human labour to gather the materials, check their accuracy and present them in a userfriendly format. Obviously database makers are not ready to make this effort if they cannot recoup their investment. Thus, in order to take the business decision to invest in making a database and commercialize it, they need to protect themselves against free-riding.

Traditionally, databases have been protected by copyright. ${ }^{2}$ Depending on the country, copyright protected the investment (and thereby the database's contents) or just the structure (classification effort) of the database. In common law countries, copyright traditionally protects labour or, as also known, 'sweat of the brow', whereas in civil law countries, copyright protects creativity. Until the

1 Williams 2000, pp. xvii-xviii. Authors of books and articles will be cited by name and date only. The full references appear in the bibliography.

2 Unless otherwise stated, the term 'copyright' will be used to describe both copyright sensu stricto (common law notion) and author's right. 
beginning of the 1990s, the problem of database protection ${ }^{3}$ in the United States of America did not arise as most courts did protect the sweat of the brow expended in creating them. But in 1991, in a landmark decision concerning a white pages directory, ${ }^{4}$ the Supreme Court reversed this line of precedent and ruled that the criterion of originality was a 'modicum of creativity' and not mere labour. Investment in making databases was therefore left without effective protection. On the other hand, in Europe,${ }^{5}$ in view of the lack of database protection owing to the high level of originality, some legislators had enacted special protection. ${ }^{6}$ In other Member States, no special legislation existed but the unfair competition tort of parasitism, slavish copying or imitation ${ }^{7}$ imperfectly protected such investment. In the United Kingdom, by contrast, databases were adequately protected by copyright.

The beginning of the 1990s marked the increase of digitization and the advent of the widespread use of the internet. With them came the ability to make perfect, fast and almost costless copies and consequently an incredibly easy way to free-ride. This exacerbated the need to protect databases. The European Community saw digitization as a threat to investment and in 1992 produced a draft Directive to protect databases. The Database Directive was adopted in 1996, creating a new intellectual property right (the sui generis right, also called 'database right') based on reciprocity, thus leaving foreign database makers without protection in Europe. ${ }^{8}$ This triggered a reaction from the United States, which drafted bills comparable to the Community's sui generis right in order for its database makers to receive protection in Europe. ${ }^{9}$ However, none were passed. The enactment of Europe's sui generis right also triggered international efforts

3 Unless otherwise stated, the expression 'database protection' or 'the protection of databases' will be used to refer exclusively to the protection of the investment required to gather, check and/or present the contents of a database rather than the protection of its structure.

$4 \quad$ Feist Publications v Rural Telephone Service Co., 499 U.S. 340 (1991).

5 The terms 'Europe', 'the European Community', 'the Community' and 'the European Union' will be used interchangeably.

6 In the Scandinavian countries, a special catalogue rule was enacted in the 1960s to this effect (see e.g. s.49 of the Swedish Copyright Act). See e.g. Karnell 1991. Dutch copyright law has also for a long time protected collections of information by the 'geschriftenbescherming', which is a remnant of an 18th century printer's right (see art. 10 of the Dutch Copyright Act). See e.g. Hugenholtz 1989, pp.41-51, 109-18. Full reference to legislation cited in the book is found in the table of legislation.

7 These terms will be used interchangeably and will be explained in detail in Chapter 3 , section 2 .

8 Directive 96/9/EC of the European Parliament and of the Council of 11 March 1996 on the legal protection of databases, OJ L77/20, 27 March 1996. Unless otherwise stated, the term 'the Directive' will be used to refer to the Database Directive.

9 The bills will be briefly discussed in Chapter 5 . 
to conclude treaties to harmonize the protection of databases worldwide. ${ }^{10}$ Nevertheless, owing to disagreements relating to the form of protection, attempts to harmonize database protection at international level failed.

As a result, the current global legal picture is an unharmonized patchwork of laws. The European Community has a specific right to protect databases, whereas the rest of the world relies either on sweat of the brow copyright (commonwealth countries except the United States) or on unfair competition, contract, technological protection measures ('TPMs') ${ }^{11}$ and/or the legal protection against their circumvention (also called 'anti-circumvention provisions'): civil law countries and the United States do the same. This creates trade distortions as well as inadequate protection because in some countries protection is either insufficient or excessive. There is therefore a need for some international uniform and balanced protection of databases.

The implications of under-protection ${ }^{12}$ or over-protection ${ }^{13}$ are both ill-fated. As for other information goods, too little protection results in an undersupply of databases. ${ }^{14}$ Left with insufficient protection, database producers do not invest for fear of free-riding. On the other hand, too much protection can lead to monopolies and potential abuses (for example, refusals to grant access or access granted at too high prices) and to the lock-up of information. Both scenarios are detrimental to society. ${ }^{15}$ Free market economies' goal is to achieve optimal social welfare. It is therefore desirable for society to have access to a high

10 Draft Treaty on intellectual property in respect of databases, WIPO, 2-20 December 1996, reproduced in M. Dellebeke 1997, pp.520-23.

11 The term 'TPMs' will be used throughout the volume to designate all sorts of devices protecting works because it is the most neutral term capable of encompassing all of them. It is also the term used in all laws prohibiting their circumvention and the term mostly used in the literature. See Dusollier 2005a, pp.38-9.

12 Under-protection occurs when database producers cannot protect their investment effectively against free-riding. This happens for instance when copyright protects only the database's structure and there is no other means to protect the database contents, or when the other means of protection are not sufficiently protective.

13 Over-protection can result from a single protection, for instance if the sui generis right is in itself too protective. It can also arise from the cumulation of several similar protections on a single subject-matter, for instance the cumulation of contract and parasitism on database contents or the cumulation of the latter two and the sui generis right on database contents. Finally, over-protection can also result from renewed protection of a database which has already obtained protection, or protection of a database which has not attracted any investment. For more detail, see Chapter 1, section 3.

14 Economists generally agree that some form of protection is necessary. For more detail, see Chapter 1, section 2.4.

15 By society, we mean all members of society as a whole. This includes database end-users and other database producers who want to reuse information to create new, different or better databases. 
number of databases because they allow better access to knowledge which in turn improves the conduct of business and research. In both scenarios (underand over-protection), society is left with too few or no databases, and social welfare is not achieved.

Society's challenge is to find the adequate level and type of protection for databases. To achieve this, the interests of, on the one hand, database producers (protection against free-riding) and, on the other, the end-users and downstream database producers (reasonable access to data to do business, conduct research or to create new databases) must be adequately balanced. The book's aim is to attempt to find such adequate protection.

\section{METHODOLOGY}

The review of the historic reasons for database protection and of the copyright justifications in Chapter 1 shows that it is desirable to protect databases. ${ }^{16}$ As stated above, the crux of the problem is to find the right balance between the database producers' and the database users' interests. The study examines different types of protection which protect the investment necessary to create databases, namely the sui generis right, the unfair competition tort of misappropriation or parasitism, ${ }^{17}$ contracts, TPMs and anti-circumvention provisions. The book will show that each, on its own, is inadequate (it either offers too much or not enough protection) and that the combination of each without appropriate safeguards is also inadequate (it is excessive and opaque, resulting in the law being unnecessarily too complex). The right balance is not achieved. The volume's ultimate goal is to remedy this problem and suggest a model law for the protection of databases which can be adopted nationally and internationally.

In order to elaborate a global model for database protection, a comparison of the manner in which the laws of several countries protect databases is in order. This is useful to identify in which country, if one at all, databases are most adequately protected. ${ }^{18}$ It has been said that 'comparative analysis contains a

16 In addition, even the sharpest critics of the sui generis right admit that databases should be protected somehow. See Maurer, Hugenholtz and Onsrud 2001, pp.789-90; Reichman and Samuelson 1997.

17 'Misappropriation' is the term used in the United States while 'parasitism' is the term used in France.

18 Zweigert and Kötz 1998, p. 46 note that the comparison of the way several legal systems tackle a specific point of law will generally bring to light which system does it best. In turn, it will help in the preparation of projects for the international unification of law (mainly the drafting of a model law so that a treaty can be adopted). Having a common law has a triple benefit: it reduces discrepancies in national systems, makes in- 
"dialectical tension"" ${ }^{19}$ On the one hand, for the analysis to be meaningful, the objects must share some identical or similar points. On the other, if there is total identity or similarity between the points compared, the analysis is meaningless. ${ }^{20}$ In this connection, the choice of the several types of laws protecting databases as objects of comparison is appropriate. All these laws share the same goal: protecting investment in making databases. However, the way these various legal means do so and the amount of protection they grant differs significantly. This leads to lack of harmonization and correlative over- or under-protection. The fact that the various protections can be combined also raises possible problems of over-protection. First, unfair competition laws have not yet been harmonized in Europe. To illustrate how the sui generis right can be combined with unfair competition, and to show that there is in this respect over-protection in some Member States and not others, two Member States (France and the United Kingdom) with very different legal traditions as far as unfair competition is concerned have been chosen. The problem of the additional protection of sui generis right-protected databases by contract and TPMs and anti-circumvention provisions is partly tackled in EU law and partly left to the individual Member States. This leaves the law partly unharmonized, allowing potential over-protection. Again the examination of French and British law is sufficient to show this.

The law of the United States is also reviewed as a further illustration of the inadequacy of each type of protection by itself or in combination to protect databases. A comparison is also justified as both legal systems have the same problem (how to protect databases adequately) and attempt to solve it by a mix of several similar protections (the main difference between the two systems is that a specific database protection, the sui generis right, exists in Europe but not in the United States). Therefore, the legal solutions and abundant literature informing the same problems facing Europe cannot simply be ignored. Finally, another obvious reason for choosing the European Union and the United States legal systems is their considerable power to influence international negotiations on the adoption of an international database protection treaty. The now greatly enlarged European Union has a uniform specific right to protect databases, while the United States continues to reject such protection. The way these countries protect databases will influence the type of database protection to be adopted in a future treaty.

ternational business easier and increases legal certainty and predictability (ibid., pp. 24-5).

19 Cappelletti, Seccombe and Weiler 1985, at 9, cited by Geradin 1997, p. 5. Unless otherwise stated in the book, footnotes in quotations are omitted.

20 Geradin 1997, p.5. 
Since much has been written on the legislative history of the sui generis right, on the United States draft database bills and the 1996 Draft Database Treaty, this book will not repeat it. References to some main works suffice to give the reader an overview. ${ }^{21}$ The book's topic is the achievement of the proper amount of protection for investment in making databases which are made available to the public by their producers. Therefore, it will not touch upon protection of the data contained in databases against invasions of privacy. Similarly, the protection of databases by the law of confidence or trade secrets is not reviewed. Copyright protection of databases is also excluded since copyright in databases (at least in the countries reviewed) does not protect content but form. The book will therefore concentrate on the protection of databases which cannot obtain copyright protection. Although relevant to the topic, but for reasons of space, the protection of databases by trespass to chattels and the Computer Fraud and Abuse Act is eschewed. ${ }^{22}$ Similarly, although it is an important means to fight over-protection, the book does not envisage the relationship between the sui generis right and competition law. In fact, as will be seen at the end of the analysis, the aim is to make the model law as balanced as possible to avoid the resort to competition law. Finally, because the study seeks the adequate protection which is based on the protection/access paradigm, only those aspects of the protection which determine protection and access will be reviewed. This entails the review of the definition of subject-matter, criterion of protection, scope, limitations and term for the sui generis right, and the examination of the corresponding provisions for the other means of protection.

Most of the study is a theoretical analysis of the statutory law in force and reported judicial decisions in each of the four countries analysed. This includes the Community primary and secondary legislation and the case law of the European Court of Justice ('ECJ') and Court of First Instance ('CFI') as well as each individual country's statutes and decisions. To formulate recommendations as to the appropriate form of database protection, the study also draws on the extensive academic literature written in the European Union and the United States. This includes articles, treatises, commentaries and previous theses. While the book does not include a detailed overview of the various American draft database bills, their relevant provisions will be briefly considered as they provide guidance to formulate a balanced model for database protection. As far as the sui generis right is concerned, a few precisions must be added. The analysis focuses on the Directive but the implementation laws of the United Kingdom and France are also examined when the Directive left an option to the Member

21 Gaster 1999; Leistner 2000b; Davison 2003; Westkamp 2003a.

22 Computer Fraud and Abuse Act, 18 U.S.C. $\$ 1030$ (2002). For a discussion, see e.g. Band and Kono 2001, pp. 869-70; Roush 2002, pp.275-6, 281. 
States (mainly the three optional exceptions provided in art. 9 of the Directive). The book is therefore not a review of whether these two countries have correctly implemented the Directive. ${ }^{23}$ References are occasionally made to the preparatory materials of the Directive when necessary to understand or interpret the law. ${ }^{24}$ The analysis of the sui generis right is not confined to the two European countries chosen, but draws, when possible, on the relevant available decisions and literature of the other Member States.

\section{STRUCTURE OF THE BOOK}

The book consists of an introduction, 10 chapters and a conclusion. After showing that databases need some form of protection, the first chapter's aim is to ascertain what criterion is to be used to determine an adequate protection of databases. Because databases are information goods traditionally protected by copyright, the classical copyright justifications are reviewed as well as the more recent justification based on human rights. This chapter will establish the 'red line' which will be followed throughout the study as it will give the criterion to gauge whether a specific protection or the addition of several protections is under- or over-protective. Ultimately it will help to decide which protection is best for databases.

Thereafter, Part I (Chapters 2, 3, 4 and 5) analyses the protection of databases in Europe. Chapter 2 reviews the protection by the sui generis right. This chapter's aim is to analyse whether the European Community, which created a specific intellectual property right to protect databases and attempted to achieve the right balance between protection and access, actually did so. Chapter 3 analyses if, and if so, how the United Kingdom and France protect databases by the unfair competition theory of parasitism, while Chapters 4 and 5 analyse how EU law (namely the Database and Copyright Directives ${ }^{25}$ ) and these Member States accommodate the possibility to override the sui generis right's limits, respectively by contract, TPMs and anti-circumvention provisions. At the end

\footnotetext{
23 For such a review, see Nauta Dutilh 2003.

24 While neither the Green Paper on Copyright and the challenge of technology, COM (88)172 final, 7 June 1988 ('the Green Paper'), nor the Explanatory Memorandum to the Directive, OJ C/156, 23 June 1992 ('the Explanatory Memorandum'), nor the recitals of the Directive bind judges, this is where they generally turn their heads to find out what the framers intended to mean. Stamatoudi 2000, p. 31.

25 Directive 2001/29/EC of the European Parliament and of the Council of 22 May 2001 on the harmonization of certain aspects of copyright and related rights in the information society, OJ L167/10, 22 June 2001 (further referred to as the 'Copyright Directive').
} 
of Part I, conclusions are drawn as to whether the sui generis right alone and/or in combination with parasitism, contracts, TPMs and anti-circumvention provisions over- or under-protects databases in Europe. The conclusion will also determine whether the possibility to cumulate several protections on databases disharmonized rather than harmonized the law.

Part II (Chapters 6, 7 and 8) respectively examines the American tort of misappropriation, contract law, the protection of databases by TPMs and the legal provisions against their circumvention and answers the questions whether such protections in themselves and in combination are over- or under-protective. The analysis of Parts I and II will reveal, while contracts, TPMs and anti-circumvention provisions are inadequate to protect databases efficiently, which of unfair competition (misappropriation or parasitism) or an intellectual property right are better alternatives.

The final part therefore aims at finding out which of the two is the more adequate protection. To this aim, Chapter 9 first reviews the differences between the two protections. It then assesses the respective merits of each protection, bearing in mind the criterion elaborated in the first chapter. Finally, Chapter 10 proposes remedies for over- and under-protection identified in Parts I and II and suggests a carefully balanced model for database protection. In conclusion, the study recommends adopting this model both nationally and internationally. 